ARTÍCULOS 



\title{
INDICADORES DE SOSTENIBILIDAD TURÍSTICA APLICADOS AL PATRIMONIO INDUSTRIAL Y MINERO: EVALUACIÓN DE RESULTADOS EN ALGUNOS CASOS DE ESTUDIO'
}

\author{
Carlos J. Pardo Abad \\ Departamento de Geografía. Universidad Nacional de Educación a Distancia (UNED) \\ cjpardo@geo.uned.es
}

\section{RESUMEN}

El turismo de patrimonio industrial es una modalidad con un alto potencial cultural en las zonas de destino, con experiencias ya consolidadas, ideas innovadoras y prácticas planificadas para la puesta en valor de los recursos locales. Sin embargo, aún no se ha investigado en profundidad su sostenibilidad. Este artículo pretende resaltar el nivel de relación que esta modalidad turística mantiene con el desarrollo sostenible a través de una serie de componentes e indicadores de fácil medición.

Palabras clave: Patrimonio industrial, patrimonio minero, turismo, desarrollo sostenible.

\begin{abstract}
Indicators of touristic sustainability applied to the industrial and mining heritage: evaluation of results in some case studies. Industrial heritage tourism is a form with a high cultural potential target in areas with consolidated experiences, innovative ideas and practical plans for enhancement of local resources. But not yet its sustainability has been deeply investigated. This article aims to highlight the level of relationship that holds this type of tourism to sustainable development through a number of components and indicators easy to measure.
\end{abstract}

Key words: Industrial heritage, mining heritage, tourism, sustainable development.

Fecha de recepción: abril 2012.

Fecha de aceptación: marzo 2013.

1 Este trabajo se inscribe en el Proyecto de Investigación $\mathrm{I}+\mathrm{D}+\mathrm{i}$ financiado por el Ministerio de Ciencia e Innovación, Plan Nacional 2008-2011, convocatoria 2011. Referencia: CSO2011-24966. 


\section{INTRODUCCIÓN}

Las antiguas fábricas y áreas mineras recuperadas se han convertido en la faceta más visible de las nuevas tendencias turísticas. Su dimensión básicamente local ha sido capaz de impulsar la economía en las áreas marcadas anteriormente por la desindustrialización, el cierre de empresas y el paro. Impulso que ha ido acompañado, con diferentes niveles de intensidad, de la sostenibilidad de los proyectos emprendidos y el respeto al medio natural y social.

En este escenario cabe plantearse de forma previa, a manera de hipótesis de partida, algunas preguntas relacionadas con los resultados económicos finales, los riesgos a los que se han enfrentado las comunidades locales, las ventajas e inconvenientes de un producto turístico tan específico, el nivel real de protección del patrimonio construido, la promoción y gestión integrada de los elementos heredados de la industrialización, la coherencia ambiental de los proyectos, etc.

Toda actividad turística presenta impactos positivos y negativos sobre las comunidades. El turismo reactiva la economía y el empleo, pero también crea graves problemas estructurales cuando se aplica de forma desaforada. Lo ideal es una asociación entre turismo y desarrollo local fundamentada en la armonía y los principios de la sostenibilidad, alejándose de las fórmulas tradicionales de turismo masivo en áreas de costa que tuvo su gran eclosión en la década de 1970.

Los territorios de tradición productiva han encontrado en el turismo un estímulo para la revalorización de sus señas de identidad, basadas tanto en aspectos culturales de carácter material como inmaterial. Esta modalidad turística se aleja de los criterios homogeneizadores impuestos en otras zonas, en donde se registra una importante densificación en determinados periodos del año. El patrimonio heredado de las industrias y minas es un recurso cultural que, a tal efecto, contribuye a desestacionalizar la demanda turística y a diversificar los atractivos en beneficio de las áreas de destino.

Esta investigación centra su análisis en la gestión y uso sostenibles del patrimonio industrial, en algunos enclaves significativos que atienden a la diversidad y complejidad de un gran legado. El impacto que la actividad productiva tuvo en su momento, bien en forma de extracción minera o de elaboración industrial, fue un factor común que se manifestó a nivel económico, demográfico, social y ambiental, con impactos de gran magnitud y transformaciones aún visibles en el paisaje.

Entendiendo la diversidad de los casos existentes, el objetivo principal es la aproximación al nivel de sostenibilidad alcanzado con el nuevo uso turístico. Interpretado frecuentemente el patrimonio industrial y minero como un recurso de revitalización local, se ha hecho imprescindible la búsqueda y selección de los indicadores más adecuados, planteando los fundamentos de la planificación y las actuaciones emprendidas.

La planificación es una herramienta irrenunciable para alcanzar los objetivos de la calidad y sostenibilidad exigidos a cualquier producto turístico. Con más razón cuando se trata de espacios afectados por el abandono de la actividad productiva y el deterioro del paisaje. La recuperación pasa, en primer lugar, por el diagnóstico previo de la situación y, posteriormente, por la definición de estrategias y objetivos que sirvan para el desarrollo de actuaciones concretas de ámbito local. 
Otro objetivo ha sido confrontar la situación de partida de las áreas seleccionadas con la alcanzada en fechas más recientes ante las expectativas abiertas por el turismo cultural. Esto ha permitido, de forma general, aunque con diferentes grados de intensidad, superar los problemas derivados del declive inicial y propiciar unos mejores niveles de desarrollo y bienestar. El empleo generado no ha alcanzado cifras elevadas, pero ha permitido la implicación de la población local y la creación de puestos cualificados sin carácter estacional.

Todo proceso de sostenibilidad turística en torno al legado material de la industrialización exige la aplicación de medidas encaminadas a facilitar la conservación y reutilización, propiciando iniciativas de gestión integradoras y respetuosas con el medio natural y social. La superación de problemas y conflictos es prioritaria y debe de servir como base para lograr actuaciones eficaces que mejoren progresivamente los resultados iniciales de la sostenibilidad.

El turismo de patrimonio industrial crea productos nuevos y competitivos en el marco de una diversificación de la oferta y la demanda cada vez más compleja, lo que obliga a tomar en consideración líneas exigentes de intervención que consideren siempre el entramado territorial y su ordenación como medio para garantizar el éxito de los destinos vinculados a la producción.

El atractivo histórico, técnico y simbólico de los monumentos y lugares industriales profundiza el interés de la visita y la amplía hasta alcanzar la cultura tradicional de la zona. Es un acervo cultural en cuya valoración se incluyen tanto bienes tangibles, muebles e inmuebles, como manifestaciones intangibles de gran valor.

\section{APORTACIÓN CONCEPTUAL Y METODOLÓGICA}

Con el propósito de interpretar las relaciones que existen entre sostenibilidad y turismo cultural practicado en torno al patrimonio industrial y minero, en este estudio se han combinado los enfoques metodológicos cualitativos y cuantitativos y se ha concedido una atención especial a la percepción global de los modelos turísticos desarrollados.

La aproximación conceptual se ha basado en la revisión bibliográfica de las teorías vinculadas a la investigación, atendiendo no solo a la trascendencia del turismo sostenible sino también a la concreción de la sostenibilidad en el ámbito del patrimonio de la industria y la minería. Es una aportación novedosa, hasta ahora no analizada en profundidad, que pretende resaltar el cumplimiento de una serie de indicadores en unos enclaves seleccionados por su significación turística y cultural, además de definir el concepto de turismo sostenible de patrimonio industrial.

Una parte fundamental de la metodología ha sido el uso de documentos literales, cartográficos y fotográficos, el trabajo de campo y la observación directa de los elementos, la elaboración de encuestas y el estudio de casos concretos. El ámbito de análisis trasciende cualquier contextualización regional para centrarse en el perfil básico de sostenibilidad en lugares específicos y representativos de lo que significa actualmente este tipo de turismo. Esto crea un modelo de valoración local que puede servir de proyección para futuros desarrollos turísticos en ámbitos geográficos de mayor escala. Los enclaves analizados se reparten por Asturias, País Vasco, Cataluña, Aragón, Castilla-La Mancha, Murcia y Andalucía (Figura 1) 


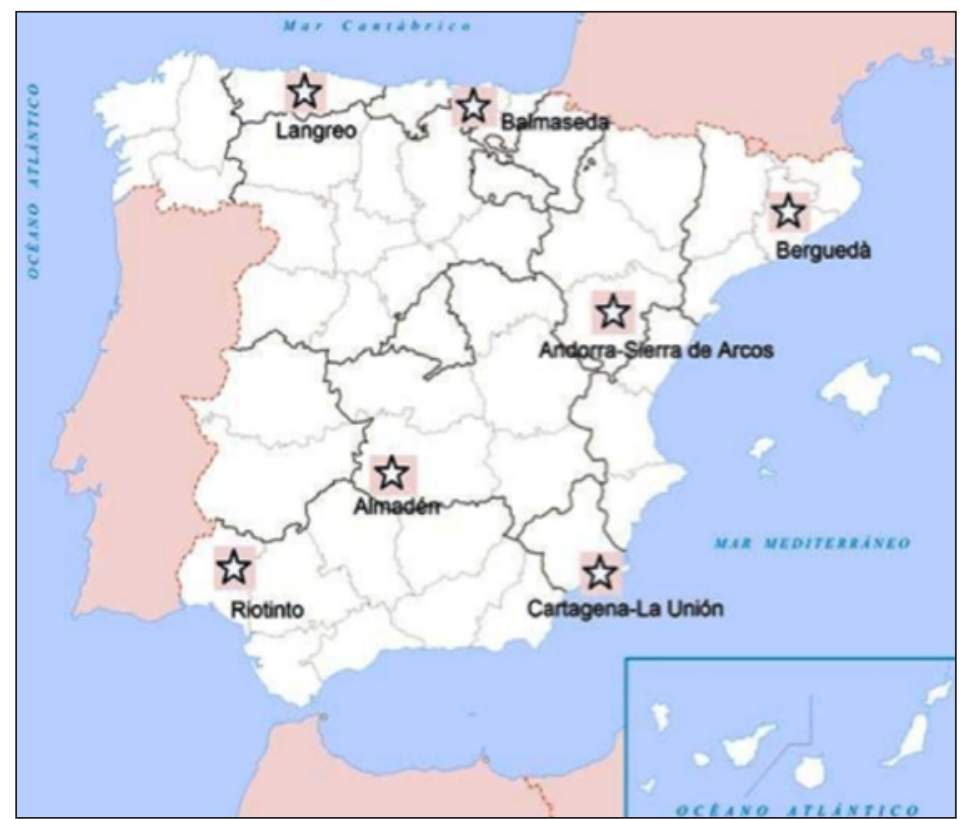

En todos los casos existe un importante patrimonio industrial, que trasciende lo tangible para abarcar las manifestaciones inmateriales aún presentes en la cultura popular, y unos vínculos con el entorno natural que obligan a establecer como estrategia de intervención la aplicación de actuaciones de vanguardia que consigan su transformación como destinos perdurables para el turismo.

Conforme al objetivo general de vincular la sostenibilidad al patrimonio minero e industrial y de construir un perfil determinado para cada enclave, se han establecido cuatro componentes generales que abarcan, a su vez, un conjunto de 23 indicadores específicos. Son los siguientes:

- Gestión eficaz e integrada de los recursos culturales y naturales: cumplimiento de los requisitos locales de zonificación, criterios exigentes de rehabilitación y protección, ofrecimiento de información e interpretación a los visitantes...

- Maximización de beneficios sociales y económicos a la comunidad local: mejora de infraestructuras, generación de empleo, colaboración de la población local, incremento de la oferta de equipamientos...

- Maximización de beneficios culturales: reducción de los impactos causados por los visitantes al patrimonio natural y construido, protección de los lugares o edificios históricos, impulso de la cultura local como parte del producto turístico vinculado al legado de la industrialización, realización de actividades con potencialidad turística... 
- Maximización de beneficios ambientales: recuperación del entorno, conservación de recursos, fomento de energías renovables, reducción de la contaminación, regulación tanto del consumo de agua como del manejo de desechos, conexión del patrimonio construido con el medio natural...

Atendiendo a estos cuatro componentes se ha diseñado en la investigación un índice sintético de desarrollo sostenible (ISDS), calculado como media para los valores de los cuatro componentes en cada lugar seleccionado, aunque su aplicación resultaría igualmente válida en otros ámbitos. A partir de los datos obtenidos de visitas turísticas se ha procedido también a calcular la relación entre esta variable y la sostenibilidad previamente calculada, obteniendo un valor final que indica una correlación positiva bastante elevada.

\section{BASES TEÓRICAS DE LA INVESTIGACIÓN}

Los desafíos que plantea el rápido crecimiento de las distintas corrientes turísticas exigen avanzar hacia un modelo, más complejo pero a la vez mejor estructurado, encaminado a garantizar la viabilidad de la actividad turística con criterios de sostenibilidad.

El concepto de sostenibilidad arranca en la década de 1970, con la celebración de algunas conferencias (Estocolmo, 1972) y la firma de algunos convenios (París, 1972) que representan los primeros compromisos a nivel internacional para la conservación de la naturaleza y la cultura. Desde entonces creció la preocupación hacia estos temas, así como los acuerdos entre naciones, hasta que en 1987 la Comisión Mundial para el Medio Ambiente y el Desarrollo elaboró un informe para la Asamblea General de las Naciones Unidas titulado Nuestro Futuro Común, más conocido como Informe Brundtland. En él se definió al desarrollo sostenible como «aquel que responde a las necesidades del presente sin comprometer la capacidad de las generaciones futuras para responder a las suyas propias».

En la década de 1990 se profundizó en la idea del desarrollo sostenible, a la par que se extendía la globalización y se incrementaban los problemas ambientales. En 1992 tuvo lugar la Cumbre de la Tierra en Río de Janeiro y se dio un énfasis particular a la sostenibilidad en relación con el avance social, económico y el medio ambiente.

La sostenibilidad adquirió pronto un carácter institucional, celebrándose cada vez más foros de discusión en los que este concepto, más allá de su aplicación real, se convirtió sobre todo en una moda. Y también en el campo del turismo, describiéndose a comienzos de la década de 1990 al turismo sostenible como el que «mantiene un equilibrio entre los intereses sociales, económicos y ecológicos» (Asociación Internacional de Expertos Científicos del Turismo, 1991), o como el que «responde a las necesidades de los turistas actuales y las regiones receptivas, protegiendo y agrandando las oportunidades de futuro» (Organización Mundial del Turismo, 1993).

En 1995 se celebró en Lanzarote la I Conferencia Mundial para el Turismo Sostenible, auspiciada por la ONU y la OMT entre otras instituciones. Se pusieron las bases para una estrategia turística mundial que garantizase el desarrollo sostenible. De los principios adoptados destaca el que define al turismo sostenible como «soportable ecológicamente a largo plazo, viable económicamente y equitativo desde una perspectiva ética y social para las comunidades locales». 
En 2002 se celebró la Cumbre Mundial sobre el Desarrollo Sostenible en Johannesburgo y se aprobó un plan de aplicación que incluía una serie de objetivos principales. Fueron asumidos rápidamente por una gran parte de países y los adoptaron en las más diversas políticas (agrícola, pesquera, energética, turística, transportes...), lo que vino a significar que se otorgaba a la sostenibilidad el papel de desafío global. Con la intención de materializar este principio, se entendió que el turismo debía integrarse en el entorno natural, cultural y humano respetando los frágiles equilibrios que caracterizan a muchos destinos turísticos, entre los que se encuentran los vinculados al patrimonio industrial.

La estrategia europea más reciente se encuadra en la denominada Carta Europea de Turismo Sostenible, cuya segunda fase de aplicación fue aprobada en el año 2007. En este documento se recogen bastantes recomendaciones para alcanzar un desarrollo turístico sostenible, favoreciendo la coherencia de las acciones que se lleven a cabo en el territorio con una perspectiva a largo plazo de la gestión del área. La conservación y mejora del patrimonio, tanto natural como histórico o cultural, se considera fundamental, así como el fomento de las actividades basadas en este patrimonio y la evaluación de los recursos disponibles.

El principio de la sostenibilidad se ha interpretado, dentro de la política turística, como un medio de desarrollo local. El elemento fundamental que debe imponerse para salvaguardar los valores esenciales vinculados al patrimonio es el equilibrio entre explotación y conservación. Para ello ha de lograrse la máxima coordinación entre las diferentes administraciones, la promoción de la iniciativa privada y el fomento del uso sostenible de la riqueza patrimonial (Sanz, 2008).

También es imprescindible la aplicación de proyectos de gestión integrados en las políticas urbanísticas, territoriales, turísticas y culturales, así como en la economía y la sociedad de las áreas receptoras (Troitiño, 2007). La iniciativa local, entendida básicamente como participación activa de la población y de las instituciones correspondientes, es clave por la singularidad de cada área. Ello hace posible la aplicación de modelos de carácter endógeno que permiten atender la complejidad del turismo en cuanto sistema transversal de actividad y superar las tendencias tradicionales de máxima rentabilidad de los recursos culturales.

La interacción entre turismo y patrimonio quedó destacada en la Carta de Turismo Cultural de ICOMOS (1999), ya que las motivaciones culturales son cada vez más importantes en los desplazamientos turísticos. Y la calidad de los destinos pasa por el uso sostenible del patrimonio, lo que se convierte en un atractivo diferenciador que potencia la llegada de visitantes (Prats, 2007).

Algunos autores apuntan que el concepto de la sostenibilidad se ha aplicado al turismo con mucha confusión y ambigüedad, agravado por la gran profusión de formas específicas de turismo y de definiciones diferentes o poco precisas de desarrollo sostenible (Butler, 1999). Lo más extendido ha sido reivindicar que cualquier turismo de pequeña escala es sostenible, focalizado en lo ambiental y cultural y con participación de la comunidad local, pero es necesario ahondar más y emplear indicadores que permitan analizar la situación real y los efectos de futuro.

Se han sugerido algunas líneas para interpretar al turismo en el contexto de la sostenibilidad y hacerlo coincidir en gran medida con los criterios generales aplicados al desarrollo sostenible. Esas líneas atenderían la perspectiva económica, ecológica y ambiental (tanto a nivel físico como humano) y de viabilidad de los proyectos a largo plazo (Coccossis, 1996). 
En otros casos se añaden algunas líneas interpretativas más, que se sumarían a las ya expuestas: política, gubernamental y administrativa (Bramwell y otros, 1996), lo que explica los diferentes abordajes en torno al concepto de la sostenibilidad y su posterior aplicación al ámbito turístico. En muchas ocasiones, el turismo sostenible ha sido entendido solo como forma duradera de turismo, en lugar de referirlo a la viabilidad de la actividad sin degradación para el medio.

La proyección del legado de la industrialización como recurso cultural conduce, inevitablemente, a la definición del concepto de turismo sostenible de patrimonio industrial como modalidad turística orientada a garantizar el uso y conservación de este patrimonio como recurso cultural, con el apoyo y participación de los visitantes y la comunidad local, y cuyo fin es minimizar los impactos adversos y maximizar los beneficios sociales, económicos, culturales y ambientales derivados de la práctica del turismo. Esta definición interpreta al patrimonio industrial de forma global en el marco de las acepciones más recientes de desarrollo sostenible.

\section{DIMENSIÓN TURÍSTICA Y GESTIÓN LOCAL DEL PATRIMONIO INDUSTRIAL}

Los procesos de transformación de los paisajes industriales abandonados en áreas de atracción e interés para el turismo son un reto y una apuesta para relanzar la identidad cultural de las zonas afectadas por el cambio.

La primera tarea tras el cierre es borrar todas las huellas del pasado y, dentro de lo posible, volver al paisaje natural del periodo preindustrial. Después, la prioridad debe centrarse en la aplicación de políticas tendentes a recuperar el empleo y la calidad ambiental con actividades de carácter sostenible que fomenten el desarrollo local. En este sentido, el turismo es una de las mejores posibilidades dentro del contexto posterior al abandono, poniéndose en valor las potencialidades de los lugares con patrimonio industrial (incluyendo también el minero) dentro de una política integrada de impulso económico (Jansen-Verbeke, 1999).

Numerosos debates se han llevado a cabo en las dos últimas décadas, pero solo recientemente se ha tomado en consideración la elaboración de planes de ámbito local y regional para dirigir, desde los principios rectores e inexcusables de la sostenibilidad, los procesos de transformación de las áreas industriales y mineras abandonadas en zonas de vocación turística. En general se considera a esta modalidad turística como compatible con los objetivos del desarrollo sostenible (Cole, 2004) y se destaca como aspecto más relevante los numerosos beneficios alcanzados, de tipo social, económico y ambiental, con un enfoque que profundiza en el reconocimiento de los restos industriales y la viabilidad de los proyectos turísticos emprendidos (Benito, 2002). En otros casos se insiste en las dificultades para la generación de riqueza y empleo en los ámbitos rurales por la intervención de actores de muy distinta naturaleza e intereses dispares (Valenzuela, Palacios e Hidalgo, 2008).

Valorar la sostenibilidad de este turismo consiste en buscar una aproximación a la racionalidad de los procesos que han conservado, modificado o transformado el territorio y los elementos vinculados a la producción. La nueva cultura territorial, surgida en las últimas décadas en las sociedades más desarrolladas, ha propiciado un mayor respeto hacia los recursos y la puesta en marcha de enfoques que implementan estrategias de intervención en torno a los retos y oportunidades planteadas. 
El patrimonio industrial presenta un alcance socioeconómico que se ha ido reafirmando a medida que se ponían en valor los recursos heredados y se convertían en pilares básicos de sostenibilidad local. Más allá del reconocimiento al patrimonio construido, la sensibilización hacia la preservación ha logrado alcanzar la noción de paisaje industrial como recurso no renovable y objeto de protección (Vahí, 2010; Castillo, López y Millán, 2010). Esto ha sido fundamental desde el punto de vista geográfico y para la interpretación que hacen algunos autores del patrimonio industrial y minero como elemento de identidad que mantiene la cohesión de las comunidades locales (Benito y Alonso, 2012).

Algunos paisajes industriales y mineros han sido reconocidos como marcos de intensas relaciones naturales, económicas, sociales y culturales, centrando actuaciones que garantizan su ordenación y gestión eficaz. Son sistemas territoriales complejos que requieren tratamientos integrales asentados sobre los principios de la sostenibilidad, con decisiones unitarias, en cuanto al territorio como conjunto y, a la vez, globales, en lo referido al patrimonio (Ayuso y Delgado, 2007).

La selección de los casos de estudio en esta investigación responde al objetivo de ahondar en los procesos de nuevo uso turístico del patrimonio industrial y minero en algunas zonas tradicionalmente marcadas por la producción y la extracción mineral. Los enclaves son representativos de lo que significa el abandono de la actividad y la recuperación integral de estructuras y paisajes tras un periodo de fuerte declive económico. No son los únicos casos de áreas inicialmente desfavorecidas, pero sí algunos de los más espectaculares por los proyectos emprendidos y los resultados finales alcanzados.

El objetivo principal de esta parte del estudio es comprobar cómo, a partir de una determinada situación de cierre y abandono, se han generado nuevas expectativas de regeneración económica con unos procesos de nueva implantación turística basados en los principios de la sostenibilidad.

Todos los enclaves seleccionados cuentan con un valioso patrimonio, heredado de un brillante pasado industrial o minero revalorizado luego por el turismo. Los lugares mineros son más espectaculares que los industriales por el hecho de haber padecido con mayor intensidad el deterioro paisajístico, así como por haber sido objeto de recuperación con proyectos más audaces e integrados en áreas de escasa o nula tradición turística. El alcance de los resultados ha sido espectacular y se ha logrado transformar con éxito los viejos recursos patrimoniales en productos para el turismo.

En los cuatro enclaves mineros seleccionados se han creado parques mineros, es decir, áreas temáticas que cumplen, en primer lugar, con la labor didáctica, lúdica o investigadora de mostrar a la sociedad el tipo de actividades desarrolladas durante décadas o siglos; en segundo lugar, también cumplen con el objetivo de proteger el patrimonio heredado de las labores mineras en su ambiente geológico. Los parques mineros así definidos se han convertido en importantes atractivos turísticos capaces de generar empleo e ingresos, modificando la degradación que hubiera ocasionado el cierre mantenido de las explotaciones y sus instalaciones asociadas.

En esos enclaves se han emprendido proyectos de ejecución distintos, pero en todos los casos se ha tomado como referencia básica la definición precisa de la oferta de servicios del parque, con propuestas turístico-culturales que van desde los recorridos de las galerías subterráneas o de los espacios abiertos en superficie, a las visitas a los museos enclavados en el recinto o las instalaciones de tratamiento del mineral. 
En los lugares industriales analizados el alcance de los proyectos ha sido menor por las propias características de las estructuras recuperadas. Se han abierto museos industriales en los que se conservan las edificaciones y piezas originales de producción, recreando el ambiente anterior al cierre, o bien centros de interpretación en los que se explica al visitante, con modernos medios divulgativos, los rasgos principales del enclave industrial y su entorno próximo.

\section{Programación de intervenciones y propuestas de nuevo uso en los parques mineros}

Las minas de Almadén, al suroeste de la provincia de Ciudad Real, son el mayor yacimiento de mercurio del mundo. Fueron explotadas desde la Antigüiedad por los romanos y después por los árabes. Pero el mayor despegue se produce a partir del siglo XVI, cuando el mercurio se hace imprescindible para el método de amalgamación de la plata, extraída en grandes cantidades de los ricos yacimientos americanos. Desde entonces, y gracias a su posición estratégica, las minas estuvieron vinculadas al Estado.

Tras un decaimiento en el siglo XVII, la producción minera se incrementó en el XVIII y la población de Almadén pasó de 2.800 habitantes en 1752 a más de 7.000 en 1800. En el siglo XIX las minas se hipotecaron, concediéndose el monopolio a varios empresarios extranjeros, lo que supuso un relanzamiento de la producción que habría de alcanzar el cénit tras la Guerra Civil debido a la importancia del mercurio como metal estratégico.

El descenso del consumo y la disminución de las reservas explotables provocaron la pérdida de rentabilidad de las minas en la segunda mitad del siglo XX y el interés consiguiente por la puesta en valor del patrimonio industrial asociado. Tras el cierre definitivo de la explotación minero-metalúrgica, la zona se ha convertido en un espacio cultural de visita pública conocido como Parque Minero de Almadén.

Los promotores de la nueva puesta en valor han sido varios ministerios (Fomento, Industria, Cultura) y la Junta de Castilla-La Mancha, con aportación de importantes fondos europeos. La Fundación Almadén, creada por la empresa minera, ha gestionado y coordinado el proyecto y las iniciativas emprendidas dirigidas a la recuperación y diversificación económica de la zona.

En 2003 se aprueba el Plan Director como instrumento de diseño, planificación y control de la transformación turística de las instalaciones. Los objetivos del plan han estado en línea con la sostenibilidad, como la recuperación del conjunto patrimonial, la puesta en valor entendida como motor de desarrollo local, el fomento de un turismo cultural de calidad basado en el impulso de nuevas infraestructuras y el respeto al medio ambiente.

La adecuación a los nuevos usos ha ido precedida de diferentes estudios, tanto de tipo arquitectónico como geológico, museológico y de viabilidad, analizándose el estado de las numerosas edificaciones patrimoniales, las posibilidades de las áreas mineras y metalúrgicas, las intervenciones necesarias para su uso expositivo y las opciones de gestión sostenible, con un plan de comunicación que garantiza la conexión del proyecto con los públicos potenciales y la comunidad local.

Por lo tanto, el plan ha procurado explotar el enorme atractivo turístico y concebir el espacio como un conjunto de elementos complementarios de gran valor, fomentando la sinergia entre los diferentes recursos naturales y culturales, por un lado, y los mineros, por otro. 
Las cifras de visitantes han quedado, finalmente, por debajo de las inicialmente previstas en las estimaciones del Plan Director, que contemplaba los siguientes totales: 19.956 en 2005, 34.922 en 2006, 61.114 en 2007, 73.337 en 2008 y 88.004 en 2009. En cualquier caso, el número real (14.954 en 2010) representa una cifra importante y el inicio de un despegue que logrará colocar a Almadén y su comarca entre los destinos turísticos más emblemáticos de toda la región (Cañizares, 2008).

Varios elementos del conjunto minero están protegidos desde 1992 como Bienes de Interés Cultural (BIC), y en 2012 las minas en su conjunto fueron incorporadas a la lista de Patrimonio Mundial de la UNESCO, en reconocimiento a su valor como las minas de mercurio más grandes del mundo y ejemplo único de la explotación de este metal a lo largo de los siglos.

La recuperación ambiental ha sido una apuesta necesaria que garantiza en todos los casos la sostenibilidad y supera las profundas huellas que sobre el medio natural ha dejado la prolongada actividad extractiva. Aunque en algunas ocasiones, como Riotinto, la acusada alteración y las dimensiones de la acción antrópica trascienden el problema del impacto ambiental, para convertirse en un marco espectacular por su colorido y vistosidad, la regeneración de los espacios más degradados se hace siempre imprescindible. En 2003 finaliza toda la actividad minero-metalúrgica en Almadén y es entonces cuando se plantea el objetivo de minimizar los impactos ocasionados en el entorno. En 2004 se redactó el proyecto de rehabilitación de la escombrera de San Teodoro, iniciándose los trabajos al año siguiente. Esta escombrera recibió durante siglos tanto estériles de las labores mineras como escorias de los procesos metalúrgicos, alcanzando una superficie próxima a las 10 hectáreas y un tamaño de 3,5 millones de toneladas a base de materiales considerados peligrosos por su contenido en mercurio.

La rehabilitación ha consistido en el encapsulamiento de la escombrera para garantizar las condiciones de estabilidad y la impermeabilización superior, evitando su recarga y los efectos sobre las aguas subterráneas y suelos del entorno (Figura 2). Se han suavizado también los taludes existentes con la intención de propiciar una mejor integración de las formas, desde $\operatorname{los} 36^{\circ}$ de pendiente inicial hasta los $25^{\circ}$ actuales, más acorde con las pendientes naturales de la zona. La restauración de la cubierta vegetal ha permitido una mejor integración paisajística de las estructuras y se ha realizado mediante especies autóctonas, contando no obstante con especies de rápido crecimiento para reducir en lo posible la erosión desde un principio. El proyecto cuenta con un plan de vigilancia ambiental que velará, durante los próximos cincuenta años, por el cumplimiento de los objetivos previstos en relación con las aguas (subterráneas y superficiales), los suelos y el aire.

El enorme patrimonio industrial de la cuenca minera de Riotinto se ha convertido en un importante instrumento de desarrollo local al noreste de la provincia de Huelva. La zona ha estado históricamente configurada por las minas y ha dependido de las civilizaciones y empresas que las explotaron. El resultado es un legado cultural, tanto tangible como intangible, de gran valor y posibilidades para el turismo.

A pesar de la larga evolución minera, que se remonta incluso al Calcolítico, el periodo de explotación más intensa tuvo lugar en el siglo XIX con la llegada de los ingleses y el inicio de la extracción industrial a gran escala. Durante 81 años, hasta 1954 en que las minas retornaron al Estado español, la zona fue en realidad una colonia inglesa. La mayoría del patrimonio conservado es de esa época y el paisaje que hoy día se puede observar fue modelado en gran parte por la Rio Tinto Company Limited. 


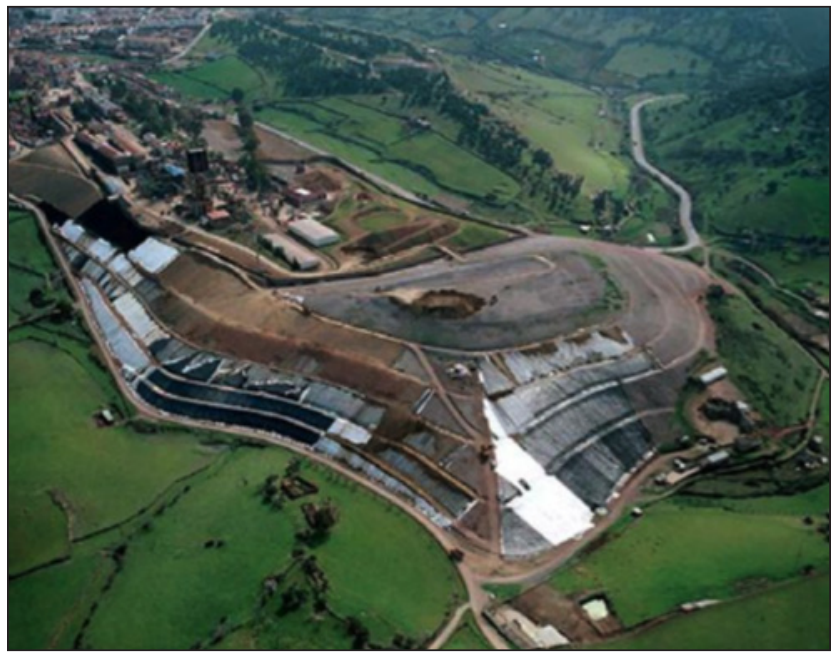

Fuente: Minas de Almadén y Arrayanes, S.A.

Se introdujo entonces la más avanzada tecnología, se implantaron nuevos usos y costumbres, se construyeron edificios victorianos y pueblos al modo de los campamentos mineros, se inauguró el ferrocarril hasta el puerto de Huelva y se controló a nivel burocrático a la población minera local. Son muy numerosos los elementos patrimoniales que componen el lugar, constituyendo una de las mayores concentraciones de Europa vinculadas al legado de la industrialización. La relación abarca poblados, cortas, escoriales, almacenes, túneles, malacates, chimeneas, abundante material ferroviario... El ferrocarril hasta el embarcadero del mineral en la ciudad de Huelva se inició en 1875, con una longitud total de $84 \mathrm{~km}$. Estuvo en funcionamiento hasta el año 1984 y en la actualidad es utilizado con fines turísticos en el tramo más próximo a la cuenca minera.

El proyecto turístico emprendido ha puesto en valor una gran parte de los elementos patrimoniales diseminados por la comarca, tomando como eje transversal de interpretación el medio natural transformado. El resultado es un parque minero que sigue las pautas de los ecomuseos, un museo de territorio en el que se han planteado varias rutas para enlazar los bienes y lugares más representativos distribuidos a lo largo de sus 900 ha. Las visitas totales han pasado de 11.366 en 1992 a 42.138 en 2002 y 69.783 en 2010.

El impulso para la creación del parque minero de Riotinto se generó desde la propia empresa minera, constituyéndose en 1987 la Fundación Rio Tinto para la gestión de uno de los más importantes patrimonios de carácter industrial y minero de España y su promoción como recurso de desarrollo endógeno y fomento del empleo local. Otros fines fundamentales son el estudio de la minería y la metalurgia, la conservación y restauración del conjunto ambiental y la difusión de los valores culturales. La búsqueda de alternativas de empleo para la población local se enmarca en los principios de la sostenibilidad, impulsándose programas formativos y la creación de escuelas taller. 
Una zona tan extensa como esta ha requerido la puesta en marcha de diferentes proyectos de ejecución, como la apertura de un museo y un archivo, la rehabilitación parcial de la línea ferroviaria, la restauración de las locomotoras y otros elementos móviles, el montaje museográfico de la Casa 21 del barrio inglés de Bellavista, etc.

La cuenca quedó protegida en 2005 como Bien de Interés Cultural con la categoría de Sitio Histórico, al amparo de la Ley de Patrimonio Histórico Andaluz de 1991. La revisión de dicha ley en 2007 ha permitido incoar procedimiento para inscribir la zona bajo la tipología de Zona Patrimonial. Esta nueva figura de protección, más acorde con el desarrollo sostenible de ámbito local, recoge los territorios o espacios que constituyen un conjunto patrimonial integrado por bienes diacrónicos representativos de la trayectoria histórica, con posibilidades de uso y disfrute y, en su caso, con altos valores paisajísticos y ambientales.

La Sierra de Cartagena-La Unión constituye el extremo suroriental de las Cordilleras Béticas, se localiza en el borde meridional de la Región de Murcia y ocupa una superficie aproximada de $100 \mathrm{~km}^{2}$. La zona ha estado muy ligada a la minería desde el siglo III a. C., con periodos de mayor o menor actividad hasta el siglo XIX. Es entonces cuando se intensifica la producción y surgen numerosas instalaciones mineras por toda la sierra vinculadas a la extracción de plata, plomo, zinc y hierro. La atracción laboral creó nuevos asentamientos, como El Llano, El Estrecho o San Ginés, y en 1860 aparece un municipio que agrega varias pedanías cartageneras, llamado La Unión.

Tras la decadencia de las primeras décadas del siglo XX, en 1950 se inicia un nuevo ciclo con la presencia de la empresa multinacional Peñarroya y la aportación de nueva tecnología, decreciendo el empleo a la vez que aumentaba el impacto ambiental. Entre 1957 y 1990 se vertieron al mar un total de 57 millones de toneladas de estériles mineros, que colmataron varias calas y la bahía de Portmán.

En 1991 cesó definitivamente la actividad extractiva y esto provocó el incremento del paro, el estancamiento poblacional y el desvío de la actividad económica hacia la construcción y los servicios en la zona próxima del litoral. Pronto surgieron las primeras iniciativas para relanzar el crecimiento de la comarca y la recuperación emprendida es un buen ejemplo del impulso de la comunidad local y varias iniciativas sociales dirigidas a favorecer el desarrollo endógeno.

Se aprobó al comienzo un proyecto, cofinanciado con fondos europeos y regionales, y se identificaron necesidades y potencialidades asociadas a la recuperación patrimonial y su nuevo uso turístico. En 1998 se crea la Fundación Sierra Minera, cuya finalidad principal es la promoción de un desarrollo equilibrado y sostenible en la zona, basado en los propios recursos naturales y culturales, particularmente su valioso patrimonio vinculado a la minería y la industria. En 2004 se crea un consorcio turístico y más recientemente, en 2009, la zona fue declarada BIC, con la categoría de Sitio Histórico. Además de su patrimonio industrial (castilletes, casas de máquinas, chimeneas, hornos de calcinación, tren minero...), su singularidad paisajística explica su actual nivel de protección y su inclusión en la lista de Paisajes Culturales Excepcionales de la UNESCO.

La programación de las intervenciones y las propuestas de uso aparecen recogidas en un Plan Director, concluido en el año 2006, que ha promovido un desarrollo sostenible basado en un turismo de patrimonio industrial de amplias potencialidades para el futuro socioeconómico de la sierra (14.650 visitantes en 2010). La rehabilitación de los elementos construidos ha sido un objetivo prioritario, como en el caso de la mina Las Matildes (hoy centro de inter- 
pretación), y a nivel ambiental también destaca la restauración paisajística del entorno, muy necesaria en espacios de intensa actividad extractiva. En este sentido se han llevado a cabo operaciones de revegetación a base de especies autóctonas que han sido capaces de desarrollarse en un sustrato con alta contaminación residual.

Recientemente se ha aprobado el proyecto de regeneración y adecuación ambiental de la bahía de Portmán y la Corta San José, tal y como quedó contemplado en 2006 en el convenio firmado entre las tres administraciones públicas, las asociaciones vecinales y las organizaciones ecologistas. Es un ejemplo de compromiso múltiple que apuesta por la protección del paisaje y el desarrollo sostenible a escala local. El proyecto va a ser financiado con fondos de cohesión europeos y contará igualmente con la participación de la Comunidad Autónoma y el Ayuntamiento de La Unión. La ejecución, que se realizará entre 2011 y 2012, pretende ser un referente a nivel europeo y mundial por la recuperación integral de un tramo costero y de la sierra, ámbitos interconectados por una larga evolución de explotación y tratamiento del mineral.

El extenso patrimonio industrial de las áreas mineras y el paisaje diferenciador e impactante de las grandes extracciones constituyen dos fortalezas para su puesta en valor, lo que representa una oportunidad de reactivación económica y regeneración del medio. La peculiaridad de estos territorios ha favorecido tanto la protección como la aprobación de proyectos ecomuseísticos, que enlazan con las propuestas europeas más innovadoras acometidas al respecto en los últimos tiempos, y la reinvención de estos lugares como destinos para el turismo (Cañizares, 2011).

El hundimiento del entramado económico de la minería hizo desaparecer en cadena, como en la zona turolense de Andorra-Sierra de Arcos a partir de 1980, toda una serie de actividades asociadas y de servicios, con pérdida de puestos de trabajo directos e indirectos y una emigración masiva hacia otras regiones. Las ayudas ofrecidas a las comarcas mineras deprimidas, desde España o la Unión Europea, produjeron resultados muy escasos debido a las características propias de estas zonas y la ausencia de iniciativas privadas de relanzamiento económico. Este ha venido, finalmente, de la mano del turismo tras la recuperación y salvaguarda del patrimonio industrial, tratando de crear las condiciones más favorables para que la actividad minera abandonada se convirtiera en un recurso para la atracción de visitantes y la creación de nuevas perspectivas de desarrollo.

Las intervenciones públicas deben ir acompañadas de la participación vecinal, con vistas a crear un producto turístico de base que sea capaz de relanzar la actividad local y regional. Colocar al patrimonio industrial en el mercado turístico es un reto que pasa por la aplicación de estrategias eficaces que modifiquen la imagen pública de abandono de estas áreas en lugares de interés y visita. Los esfuerzos requieren tiempo e inversiones, y el convencimiento a la comunidad de enlazar el pasado con el futuro mediante la conservación y rehabilitación de los sitios y edificios industriales.

Una amplia proporción de la población local no tiene vínculos con la historia productiva asociada a las fábricas y minas y puede que no esté interesada inicialmente en la recuperación de las construcciones y paisajes contaminados. La promoción juega un papel fundamental para extender la idea de que los beneficios económicos generados por una correcta planificación del turismo de patrimonio industrial acabarán convirtiendo a este legado en un símbolo cultural sentido como identitario y como estrategia para incrementar las posibilidades de desarrollo y la creación de nuevos puestos de trabajo. 
La organización paralela de actividades culturales, por ejemplo, refuerza la riqueza de la memoria y los vínculos de toda la comunidad con el pasado. Es el caso del Festival Internacional del Cante de las Minas (La Unión, Murcia) o el Mercáu Tradicional de la Revolución Industrial (La Nueva, Asturias). Un patrimonio que trasciende lo material y da sentido a la trayectoria de numerosas poblaciones íntimamente ligadas a unos territorios en los que confluyen, de forma compleja y estratificada, distintos elementos naturales, sociales, económicos y culturales.

\section{Adaptación turística de los enclaves industriales e integración en la oferta local}

Además de las áreas mineras, de fuerte impacto visual por las huellas dejadas sobre el terreno en periodos de larga explotación, algunas zonas de intensa implantación fabril han sido también objeto de un tratamiento global para la rehabilitación y gestión eficaz de sus entornos. Las actuaciones derivadas son menos impactantes que en el caso de las minas, pero igualmente encaminadas a conseguir niveles aceptables de sostenibilidad local con proyectos de nuevo uso turístico, participación de la comunidad y conservación de arquitecturas y del medio ambiente. Es el caso de los corredores patrimoniales de los ríos Llobregat y Ter en Cataluña.

Son dos ejes fluviales que han fomentado la linealidad de los asentamientos urbanos y de los sistemas de transporte, así como el establecimiento intenso de industrias. Existe en ambos casos un número muy elevado de colonias industriales, quizá la mayor concentración a nivel mundial. Son conjuntos urbano-fabriles, que destacan de manera sorprendente sobre un paisaje fundamentalmente agrario, y testimonio de una industrialización que se remonta a la segunda mitad del siglo XIX.

Al contrario que en Inglaterra, estas colonias no representan una etapa de industrialización previa y necesaria para la posterior localización urbana con el uso del vapor y la mecanización definitiva del textil, sino la reacción a la industrialización urbana que comenzó hacia 1830 y la inestabilidad laboral propia de las ciudades. El impulso vino también de la mano de una serie de leyes de Fomento que buscaban el establecimiento de población en áreas baldías del ámbito rural, como en el caso de la Ley de Colonias Agrícolas de 1855. Los privilegios fiscales y la ampliación de los objetivos al terreno industrial, a través de otra ley de 1868, desencadenaron un amplio movimiento de creación de poblados y de conversión de fábricas inicialmente aisladas en núcleos fabriles a lo largo de los citados ríos.

Las colonias del Llobregat están incluidas actualmente como objetivo prioritario en el Plan Nacional de Patrimonio Industrial, no así las del Ter. El gobierno regional ha aprobado sendos Planes Directores Urbanísticos (PDU Colònies del Llobregat, en 2007; PDU Colònies del Ter, en 2010) con carácter permanente, aunque se prevé su adaptación a las posibles modificaciones de los planes territoriales de rango superior. Las colonias se consideran elementos articuladores del territorio y su preservación es una de las principales apuestas de los planes directores para el desarrollo de un turismo cultural significativo (Figura 3). Esto se ha planteado siguiendo el concepto de parque patrimonial y en términos parecidos al Emscher Park en Alemania, con respeto hacia los valores ambientales como vía de dinamización social y económica de la zona a medio y largo plazo. 


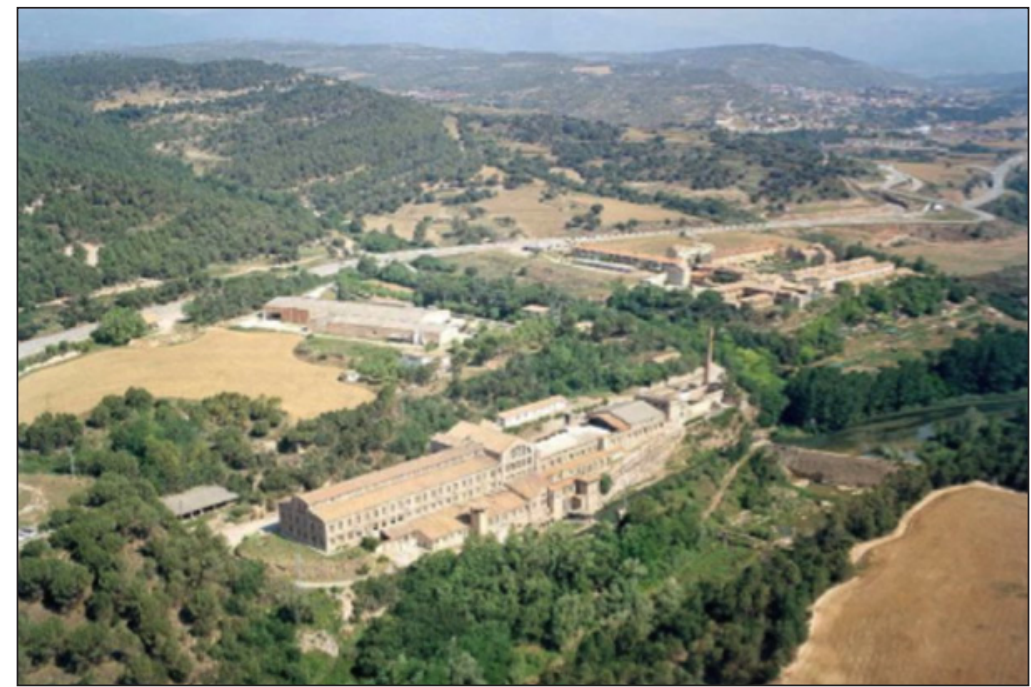

Fuente: Departament de Territori i Sostenibilitat de la Generalitat de Cataluña.

El patrimonio del Llobregat y Ter es un patrimonio vivo porque una buena parte de las colonias siguen estando habitadas, lo que provoca contradicciones a la hora de conservar el importante legado industrial y armonizar los distintos usos existentes. A la vez es un patrimonio muy complejo por los vínculos entre los distintos elementos y entre estos y el paisaje fluvial circundante. La rehabilitación planteada en los PDU es de tipo integral, de acuerdo a criterios estrictamente sostenibles, y contempla varias zonas en forma de coronas concéntricas en torno a las colonias. Más allá de dotar a estos espacios de los servicios y equipamientos necesarios, equiparándolos a los barrios de los respectivos municipios, el objetivo es consolidar el patrimonio cultural vinculado a la industrialización, transformando las colonias y fábricas de río en lugares de residencia y de actividad productiva, de frecuentación turística y de preservación de la memoria colectiva. Se fomenta, por otro lado, la imagen de las fábricas como hitos básicos de ámbito local y se reconoce la singularidad de los poblados como recintos históricos en un paisaje cultural profundamente marcado por la industria.

En 1857 se creó en Asturias la industria Duro y Compañía, conocida luego como DuroFelguera, dedicada a la producción siderúrgica y a la explotación de las minas de carbón. Localizada en la zona central de la región, aprovechaba las excelentes condiciones ofrecidas por la existencia de ferrocarril y carretera entre la cuenca central asturiana y el puerto de Gijón. La instalación de la fábrica supuso una transformación territorial sin precedentes que dio lugar al nacimiento de La Felguera a partir de tres aldeas previamente existentes. La urbanización de barrios de vivienda obrera para los trabajadores, como el barrio Urquijo (1916), la construcción de casas burguesas, un centro de asistencia sanitaria o el colegio de La Salle (1902) muestran los cambios acontecidos en torno a la vieja fábrica. 
La fábrica cerró en 1984 y al año siguiente se firmó un convenio entre el Ayuntamiento de Langreo, el gobierno regional y ENSIDESA, propietaria de la factoría desde el año 1973, por el que la empresa cedía al ayuntamiento todos los activos fijos de la fábrica. Se aprobó también un Plan Especial para introducir nuevos usos en algunos edificios objeto de conservación y liberar suelo para un polígono industrial de actividades no contaminantes, de carácter novedoso por plantearse como centro de proyectos y semillero empresarial (Ciudad Industrial de Valnalón). Un elemento conservado, de gran significación emblemática y paisajística, es el refrigerante, convertido desde 2006 en centro de interpretación del Museo de la Siderurgia (MUSI). Es un museo abierto que integra diferentes estructuras: edificios terciarios de la siderurgia construidos en estilo manchesteriano típicamente industrial, torre de refrigeración, poblado obrero, casa de dirección... La mayor particularidad es que se trata del único museo abierto de tipo urbano que existe en España, por lo que al interés patrimonial se une su gran valor didáctico al explicar el devenir de Langreo en relación con el desarrollo y posterior declive industrial de la empresa.

La fábrica de Boinas La Encartada, en Balmaseda (Vizcaya), se inauguró en 1892 como industria destinada a la producción de géneros de lana. Se construyó a las afueras del núcleo urbano, en un lugar que permitía el aprovechamiento de un salto de agua de una antigua ferrería. Alrededor se creó también una pequeña colonia obrera. La empresa, que se había dotado desde un principio de una maquinaria puntera para la época, cerró en 1992 con la misma fisonomía y casi dotación técnica inicial. En 2002, el conjunto fabril fue protegido como Bien Cultural con la categoría de Conjunto Monumental.

El aporte económico del ayuntamiento y de la Diputación Foral de Vizcaya permitió la adquisición del inmueble y sus equipamientos en 1994. Las primeras partidas presupuestarias para la rehabilitación, restauración y reforma destinadas a la creación de un museo tuvieron lugar en 1995. La colaboración realizada durante más de una década entre ambas instituciones cristalizó en 2006 en forma de fundación, abriéndose un año más tarde la fábrica-museo como uno de los complejos turísticos de patrimonio industrial con mayor interés de todo el país.

\section{Estrategias de intervención y participación de agentes}

La conversión del patrimonio industrial en recurso cultural y producto turístico exige, en casi todos los casos, la intervención de iniciativas públicas destinadas a financiar los costes de las actuaciones. Programas como LEADER, PRODER, MINER... y planes como el del Carbón y los de Dinamización Turística han sido de gran importancia para la ejecución de los proyectos. Las primeras experiencias de conversión turística del legado minero, en la década de 1990, fueron gestionadas principalmente por las administraciones locales, que buscaban en esta nueva modalidad impulsar el desarrollo económico y ofrecer alternativas de empleo tras el cierre o abandono de las explotaciones. Al amparo de los citados programas y planes, la rehabilitación de las instalaciones, la inauguración de museos mineros o el nuevo uso turístico de las viejas líneas férreas fueron las intervenciones más señaladas como parte de unos proyectos de cierta envergadura encaminados a la posterior creación de parques mineros basados en la concepción ecomuseística, que integra el elevado número de restos patrimoniales dispersos por el territorio y el potencial 
de sus recursos naturales. Es el caso del valle del Nalón, en Asturias, en donde la apertura del Museo de la Minería y la Industria en la localidad de El Entrego es una de las iniciativas más interesantes al respecto (Tapia, 2010). A partir de esta experiencia, y también del Parque Minero de Riotinto, otras localidades desarrollaron proyectos museológicos parecidos para el rescate patrimonial, el impulso económico y el refuerzo identitario de sus enclaves.

La Carta de El Bierzo, aprobada en 2008 por el Consejo de Patrimonio Histórico para la defensa y protección del patrimonio minero, concede a este legado el papel de regenerador de las comunidades desarrolladas en torno a la mina. Además de los significados históricos, materiales, técnicos y estéticos, este documento hace hincapié en los medioambientales vinculados al entorno natural. Considera fundamental, de igual modo, la participación activa de la población local en la que se ubica el complejo minero para su mejor puesta en valor y mantenimiento. Los criterios de sostenibilidad están muy presentes y se apuesta por los proyectos que respalden intervenciones basadas en las buenas prácticas, más allá de la creación final de un nuevo producto turístico.

Los ayuntamientos, aunque no siempre han asumido la plena conservación de los restos, han sido los verdaderos artífices del cambio hacia el turismo por aplicar las iniciativas de rango estatal o autonómico y por contar con la capacidad técnica para impulsar turísticamente los espacios improductivos mediante el planeamiento. También es importante su participación en las fundaciones y patronatos encargados del desarrollo, gestión y explotación de las antiguas instalaciones y sus entornos. Los patronatos, como en el caso del Museo de la Siderurgia de Langreo, garantizan la financiación de unos proyectos que casi siempre exigen acometer grandes inversiones. La demanda turística a veces no justifica plenamente las cantidades comprometidas y solo las oportunidades de desarrollo local a medio plazo que llevan aparejadas animan las iniciativas emprendidas por las instituciones, más allá de la rentabilidad económica inmediata.

En otros casos es el compromiso de las compañías propietarias, como ha sucedido en algunas zonas mineras, el factor determinante que ha facilitado la labor de adecuación turística. La recuperación de una mina a cielo abierto por ENSIDESA en Andorra-Sierra de Arcos ha creado, por ejemplo, un espacio de gran interés ambiental que se incorpora como punto de visita al parque minero inaugurado en la comarca a mediados de la década de 2000 . La intervención de la empresa también ha sido fundamental en Riotinto, impulsora de una fundación apoyada por la administración y las entidades locales y con el objetivo expreso de una gestión sostenible de los recursos y la difusión de actividades. También es el caso de Almadén, en donde la empresa MAYASA promovió la realización de un plan estratégico para ejecutar la recuperación, el tratamiento medioambiental del entorno y la inauguración de todas las instalaciones como parque minero, significando una de las mayores inversiones en la musealización del patrimonio industrial español.

La patrimonialización de los restos exige la participación de varios agentes: la comunidad local, la administración en sus distintos niveles y las empresas industriales o mineras. Cada uno de ellos desempeña un papel fundamental para el impulso turístico de los enclaves y el éxito final de los proyectos. En el mejor de los casos, los tres agentes citados aparecen coordinados e intervienen de manera activa desde un principio, lo cual garantiza la nueva experiencia de desarrollo local. 
Sin embargo, lo más frecuente es que la iniciativa sea emprendida solo por algunos de los agentes mencionados, auténticos impulsores de un cambio complejo en cuyas distintas fases pueden verse sucesivamente involucrados el resto de actores. En Almadén la iniciativa partió de la administración, en Riotinto desde la empresa minera y en Cartagena-La Unión desde la propia sociedad civil. Son tres niveles distintos que representan la variedad y la complejidad de las actuaciones iniciales emprendidas sobre el legado de la industrialización, y el compromiso con la recuperación de las estructuras construidas y los paisajes para el nuevo uso. La viabilidad de los proyectos y su previsión como recurso de desarrollo de ámbito local exige posteriormente la ampliación de los agentes implicados.

Las características propias de cada enclave condicionan, de algún modo, las formas de intervención y el grado de participación de las administraciones públicas, la comunidad local y las empresas en las distintas fases. El éxito de los proyectos analizados, referentes españoles de la mejor gestión del patrimonio industrial, va más allá de cualquier consideración parcial y confirma la importancia de la actuación global y el compromiso de los agentes públicos y privados (Valenzuela, Palacios e Hidalgo, 2008).

\section{COMPONENTES E INDICADORES DE SOSTENIBILIDAD: EVALUACIÓN DE RESULTADOS}

Tabla 1

COMPONENTES E INDICADORES DE SOSTENIBILIDAD TURISTIICA DEL PATRIMONIO INDUSTRIAL

$\begin{array}{ll} & \mathrm{I}_{1} \text { Nivel de protección patrimonial } \\ \text { Componentes de gestión } & \mathrm{I}_{2} \text { Nivel de rehabilitación patrimonial } \\ \text { (CG) } & \mathrm{I}_{3} \text { Cumplimiento de la zonificación local } \\ & \mathrm{I}_{4} \text { Información proporcionada a los visitantes } \\ & \mathrm{I}_{5} \text { Dotación de fondos económicos } \\ & \mathrm{I}_{6} \text { Aportación económica de las entidades locales } \\ & \mathrm{I}_{7} \text { Beneficios para la comunidad local } \\ \text { Componentes sociales y } & \mathrm{I}_{8} \text { Colaboración de la población local } \\ \text { económicos } & \mathrm{I}_{9} \text { Mejora de las infraestructuras } \\ \text { (CSE) } & \mathrm{I}_{10} \text { Incremento de los equipamientos } \\ & \mathrm{I}_{11} \text { Generación de nuevo empleo } \\ & \mathrm{I}_{12} \text { Procedencia local de los trabajadores empleados } \\ & \mathrm{I}_{13} \text { Nivel de satisfacción general de las visitas } \\ & \mathrm{I}_{14} \text { Impulso de la cultura local } \\ & \mathrm{I}_{15} \text { Dinamización de la oferta cultural local } \\ \text { Componentes culturales } & \mathrm{I}_{16} \text { Realización de actividades paralelas externas } \\ \text { (CC) } & \mathrm{I}_{17} \text { Nivel de satisfacción de la comunidad } \\ & \mathrm{I}_{18} \text { Apreciación de la población hacia el patrimonio industrial } \\ \text { Componentes ambientales } & \mathrm{I}_{19} \text { Nivel de recuperación ambiental del entorno } \\ & \mathrm{I}_{20} \text { Consideración estética del entorno recuperado } \\ & \mathrm{I}_{21} \text { Uso de fuentes energéticas renovables } \\ & \mathrm{I}_{22} \text { Aplicación de medidas de ahorro energético } \\ & \mathrm{I}_{23} \text { Conexión del patrimonio construido con el entorno natural } \\ & \end{array}$

Fuente: elaboración propia. 
Tabla 2

VALORES DE LOS INDICADORES DE SOSTENIBILIDAD POR CENTRO PATRIMONIAL

\begin{tabular}{|lllllllll} 
Componentes e indicadores & & PMA & PMR & PMLU & MCV & MBLE & MUSI & PTMA \\
Componentes de gestión (CG) & & & & & & & & \\
& $\mathbf{I}_{\mathbf{1}}$ & 4 & 4 & 4 & 2 & 2 & 2 & 2 \\
& $\mathbf{I}_{\mathbf{2}}$ & 3 & 4 & 3 & 2 & 4 & 2 & 1 \\
& $\mathbf{I}_{\mathbf{3}}$ & - & 4 & 4 & 2 & 2 & 2 & 2 \\
& $\mathbf{I}_{\mathbf{4}}$ & 4 & 4 & 3 & 3 & 3 & 2 & 2 \\
& $\mathbf{I}_{\mathbf{5}}$ & 3 & 3 & 2 & 1 & 1 & 1 & 1 \\
& $\mathbf{I}_{\mathbf{6}}$ & 0 & 0 & 1 & 1 & 1 & 3 & 1
\end{tabular}

\section{Componentes sociales $\mathbf{y}$} económicos

(CSE)

$\begin{array}{llllllll}\mathbf{I}_{\mathbf{7}} & 4 & 4 & 4 & 3 & 2 & 4 & 2 \\ \mathbf{I}_{\mathbf{8}} & 2 & 3 & 2 & 2 & 4 & 2 & 3 \\ \mathbf{I}_{\mathbf{9}} & 2 & 3 & 3 & 2 & 2 & 3 & 3 \\ \mathbf{I}_{\mathbf{1 0}} & 4 & 4 & 3 & 2 & 3 & 3 & 0 \\ \mathbf{I}_{\mathbf{1 1}} & 0 & 3 & 3 & 3 & 3 & 4 & 1 \\ \mathbf{I}_{\mathbf{1 2}} & 4 & 4 & 4 & 4 & 4 & 4 & 3\end{array}$

\section{Componentes culturales \\ (CC)}

$\begin{array}{llllllll}\mathbf{I}_{13} & 3 & 4 & 3 & 3 & 3 & 3 & 3 \\ \mathbf{I}_{14} & 4 & 4 & 4 & 3 & 3 & 4 & 3 \\ \mathbf{I}_{15} & 3 & 4 & 3 & 3 & 3 & 3 & 2 \\ \mathbf{I}_{16} & 2 & 4 & 3 & 3 & 4 & 2 & 1 \\ \mathbf{I}_{17} & 3 & 4 & 4 & 3 & 4 & 3 & 2 \\ \mathbf{I}_{18} & 3 & 4 & 3 & 2 & 2 & 3 & 2\end{array}$

\section{Componentes ambientales}

(CA)

$\begin{array}{llllllll}\mathbf{I}_{\mathbf{1 9}} & 4 & 4 & 3 & - & 4 & - & 3 \\ \mathbf{I}_{\mathbf{2 0}} & 4 & 3 & 3 & 3 & 4 & 2 & 2 \\ \mathbf{I}_{\mathbf{2 1}} & 2 & 2 & 2 & 3 & 4 & 0 & 1 \\ \mathbf{I}_{\mathbf{2 2}} & 3 & 4 & 3 & 3 & 4 & 0 & 2 \\ \mathbf{I}_{\mathbf{2 3}} & 3 & 4 & 4 & 4 & 3 & 3 & 3\end{array}$

Centros patrimoniales: PMA (Parque Minero de Almadén); PMR (Parque Minero de Riotinto); PMLU (Parque Minero de La Unión); MCV (Museo de la Colonia Vidal); MBLE (Museo de Boinas La Encartada); MUSI (Museo de la Siderurgia); PTMA (Parque Tecnológico Minero de Andorra-Sierra de Arcos).

Control de indicadores: 0: nada; 1: muy poco; 2: poco; 3: bastante; 4: mucho.

Fuente: encuesta postal y elaboración propia.

En la investigación se han creado cuatro componentes y 23 indicadores básicos que sirven de modelo de análisis para la sostenibilidad local en entornos de patrimonio industrial. Hay numerosas experiencias de elaboración y aplicación de indicadores, que pretenden valo- 
Tabla 3

VALORES ALCANZADOS POR COMPONENTES E ISDS

\begin{tabular}{|lccccc}
$\begin{array}{l}\text { Centro } \\
\text { patrimonial }\end{array}$ & CG & CSE & CC & CA & ISDS \\
\hline PMA & 2,8 & 2,7 & 3,0 & 3,3 & $\mathbf{2 , 9}$ \\
\hline PMR & 3,2 & 3,5 & 4,0 & 3,4 & $\mathbf{3 , 5}$ \\
\hline PMLU & 2,8 & 3,2 & 3,3 & 3,0 & $\mathbf{3 , 1}$ \\
\hline MCV & 1,8 & 2,7 & 2,8 & 3,2 & $\mathbf{2 , 6}$ \\
\hline MBLE & 2,2 & 3,0 & 3,2 & 3,8 & $\mathbf{3 , 0}$ \\
\hline MUSI & 2,0 & 3,3 & 3,0 & 1,2 & $\mathbf{2 , 4}$ \\
\hline PTMA & 1,5 & 2,0 & 2,2 & 2,2 & $\mathbf{2 , 0}$ \\
\hline $\bar{X}$ & $\mathbf{2 , 3}$ & $\mathbf{2 , 9}$ & $\mathbf{3 , 1}$ & $\mathbf{2 , 9}$ & $\mathbf{2 , 8}$ \\
\hline
\end{tabular}

Fuente: encuesta postal y elaboración propia.

rar la evolución en ámbitos de escalas muy diversas y comprobar la eficacia de las acciones adoptadas, pero ninguna referida al patrimonio industrial como recurso para el turismo.

Mediante el envío de una encuesta postal a varios centros seleccionados, entre diciembre de 2011 y enero de $2012^{2}$, se ha obtenido la información necesaria para medir la sostenibilidad turística vinculada al patrimonio industrial. El grado de respuesta ha sido plenamente satisfactorio, quizá debido al número corto de preguntas, la especificidad de los centros estudiados y el interés por dar a conocer una modalidad turística percibida aún como minoritaria.

A partir de los valores de los indicadores de sostenibilidad de la Tabla 2 se ha calculado la media de cada uno de los cuatro componentes, así como el índice sintético de desarrollo sostenible (ISDS), para todos los centros patrimoniales seleccionados (Figura 4).

Con el objetivo de analizar los resultados alcanzados en los cuatro componentes y en el ISDS, se va a proceder a continuación a comentar las cuestiones más destacables para cada uno de los centros de patrimonio industrial y minero.

\section{a) Parque Minero de Almadén (PMA)}

Presenta un valor medio-alto en el ISDS. De los cuatro componentes, el ambiental es el que tiene un mayor valor $(3,2)$, seguido del cultural $(3,0)$ y del componente de gestión $(2,8)$. La sostenibilidad referida al ámbito social y económico es menor y se sitúa por debajo de los valores medios para todos los centros, a pesar de la estrategia global emprendida en el lugar para alcanzar los máximos niveles de sostenibilidad. Indicadores más elevados: $\mathrm{I}_{1}, \mathrm{I}_{4}, \mathrm{I}_{7}, \mathrm{I}_{10}, \mathrm{I}_{12}, \mathrm{I}_{14}, \mathrm{I}_{19-20}$.

2 El envío de la encuesta se ha realizado al Parque Minero de Almadén (Ciudad Real), Parque Tecnológico Minero de Andorra-Sierra de Arcos (Teruel), Parque Minero de La Unión (Murcia), Parque Minero de Riotinto (Huelva), Museo de la Siderurgia de Langreo -MUSI- (Asturias), Museo de Boinas La Encartada de Balmaseda (Vizcaya) y Museo de la Colonia Vidal de Puig-Reig (Barcelona). 


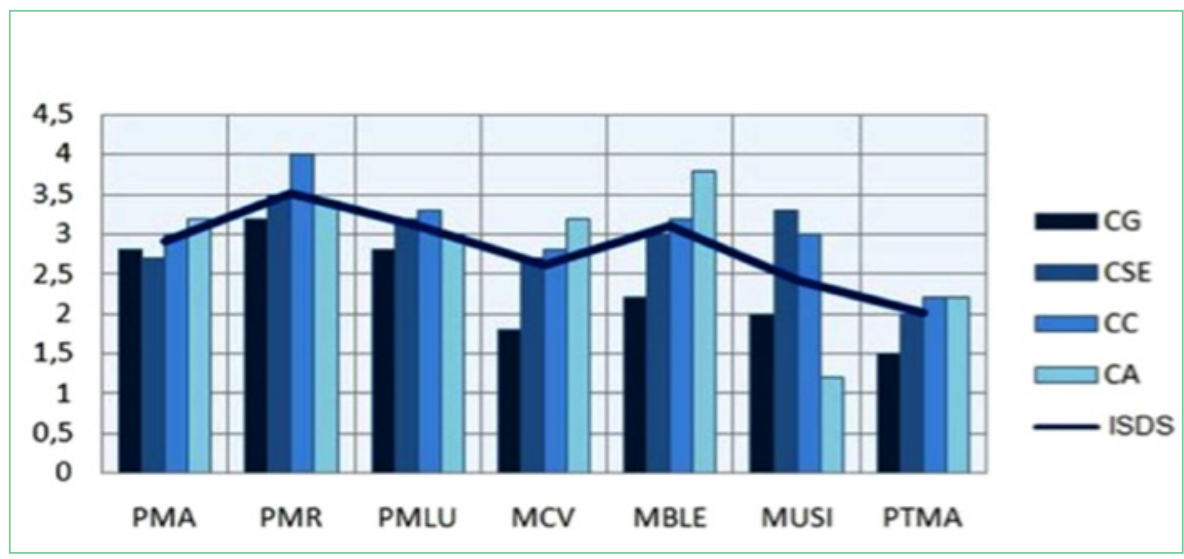

b) Parque Minero de Riotinto (PMR)

Se encuentra en la primera posición en cuanto al índice sintético de sostenibilidad. Todos los componentes descritos presentan valores medios superiores a los del conjunto, siendo el más destacado el cultural $(4,0)$, siguiendo a continuación el social y económico $(3,5)$. El componente con un valor inferior es el de gestión, quizá influido por el hecho de constituir un enclave muy amplio, con un número muy elevado de elementos que integrar en un mismo espacio interpretativo para el turismo, y la muy reducida aportación de fondos económicos por parte de las corporaciones locales. Indicadores más elevados: $\mathrm{I}_{1-4}, \mathrm{I}_{7}, \mathrm{I}_{10}, \mathrm{I}_{12}, \mathrm{I}_{13-18}, \mathrm{I}_{19}, \mathrm{I}_{22-23}$.

\section{c) Parque Minero de La Unión (PMLU)}

Tiene un valor medio-alto en el ISDS y se sitúa en segunda posición dentro del conjunto de centros de patrimonio industrial. El componente con una cifra más elevada es el cultural $(3,3)$, al que le sigue el social y económico $(3,2)$. El componente ambiental es el que presenta un valor más reducido $(3,0)$, aunque todavía por encima de la media. La degradación prolongada de la zona y la lentitud en la aplicación de las actuaciones de mejora explican esta situación de inferioridad comparativa respecto a las dos anteriores áreas mineras. Indicadores más elevados: $\mathrm{I}_{1}, \mathrm{I}_{3}, \mathrm{I}_{7}, \mathrm{I}_{12}, \mathrm{I}_{14}, \mathrm{I}_{17}, \mathrm{I}_{23}$.

\section{d) Museo de la Colonia Vidal (MCV)}

Su ISDS tiene un valor medio-bajo y ocupa el puesto quinto de los siete centros de patrimonio industrial analizados. El componente más destacado es el ambiental $(3,2)$, situado por encima de la media. A continuación destaca el cultural $(2,8)$ y el social y económico $(2,7)$. El de gestión es uno de los más bajos de todo el conjunto, fundamentalmente como consecuencia de la poca dotación de fondos económicos y de la escasa aportación de las entidades locales. Indicadores más elevados: $\mathrm{I}_{12}, \mathrm{I}_{23}$. 


\section{e) Museo de Boinas La Encartada (MBLE)}

Representa la tercera posición en la jerarquía del índice de sostenibilidad. Destaca especialmente el componente ambiental $(3,8)$, seguido del cultural $(3,2)$ y del social y económico $(3,0)$. Como en el resto de centros patrimoniales analizados, el componente de gestión es el que presenta un menor valor debido a la escasa dotación de fondos económicos. Indicadores más elevados: $\mathrm{I}_{2}, \mathrm{I}_{8}, \mathrm{I}_{12} \mathrm{I}_{16-17}, \mathrm{I}_{19-22}$.

\section{f) Museo de la Siderurgia (MUSI)}

Tiene su ISDS un valor medio-bajo dentro del conjunto. En este centro los componentes con unos valores más elevados son el social y económico $(3,3)$, que le coloca por encima de la media, en segunda posición tras el Parque Minero de Riotinto, y el cultural $(3,0)$. El ambiental es verdaderamente deficitario $(1,2)$, con la cifra más baja de la serie. Indicadores más elevados: $\mathrm{I}_{7}, \mathrm{I}_{11-12}, \mathrm{I}_{14}$.

\section{g) Parque Tecnológico Minero de Andorra-Sierra de Arcos (PTMA)}

Presenta un ISDS con un valor bajo, situándose en última posición. Los dos componentes más destacados son el cultural $(2,2)$ y el ambiental $(2,2)$, seguido del social y económico $(2,0)$. El de gestión es especialmente deficitario en la provisión de fondos y en la rehabilitación patrimonial de los elementos conservados. Indicadores más elevados: $\mathrm{I}_{8-9}, \mathrm{I}_{12-14}, \mathrm{I}_{19}, \mathrm{I}_{23}$.

La conservación ejemplar del legado y el uso turístico sostenible ha convertido a estos lugares en un referente indiscutible para todos los entornos mineros e industriales. Es un turismo muy ligado al territorio que busca reconciliar lo medioambiental y turístico a través de un equilibrio que active y dinamice la economía local, así como el imaginario colectivo de unos enclaves muy antropizados de larga trayectoria productiva y extractiva. Este patrimonio es uno de los recursos más recientes para el turismo, desarrollándose aún en la actualidad proyectos de creación de nuevos productos turísticos muy interesantes en los que se persigue el objetivo, siempre irrenunciable, de lograr un nivel de sostenibilidad adecuado al entorno social, económico y ambiental.

Aunque en algunos casos las cifras de visitantes son importantes, nunca se pueden comparar con las registradas en algunos lugares patrimoniales de otros países europeos o por otros patrimonios diferentes de lo minero-industrial en nuestro propio país. En los casos analizados, el volumen de turistas es bastante modesto, salvo en el Parque Minero de Riotinto, con unos 70.000 visitantes anuales. Almadén, La Unión y la Colonia Vidal se sitúan en el entorno aproximado de los 15.000 y el resto no alcanzaron las 10.000 visitas en el año 2010 (Figura 5). Datos verdaderamente reducidos en su conjunto que cuestionan frecuentemente las inversiones realizadas. Los beneficios, en cualquier caso, van más allá de las cifras de visitas, aunque sea uno de los indicadores más manejados para valorar el alcance real como recurso para el turismo.

Para ver la vinculación entre el índice de sostenibilidad ISDS y el número de visitantes se ha calculado un coeficiente de correlación que atiende ambas variables y cuyo valor puede situarse entre $-1,0$ (relación inversa perfecta) y 1,0 (relación directa perfecta). Con los datos 
contenidos en la Tabla 4 se ha calculado un valor de 0,688 , lo que indica una correlación positiva bastante alta entre el nivel de sostenibilidad y el número de visitantes. Se ha utilizado la siguiente ecuación:

$$
r=\frac{\frac{\sum x y}{n}-\bar{x} \bar{y}}{S x S y}
$$

Figura 5

VISITANTES ANUALES EN 2010 EN LOS CASOS ANALIZADOS

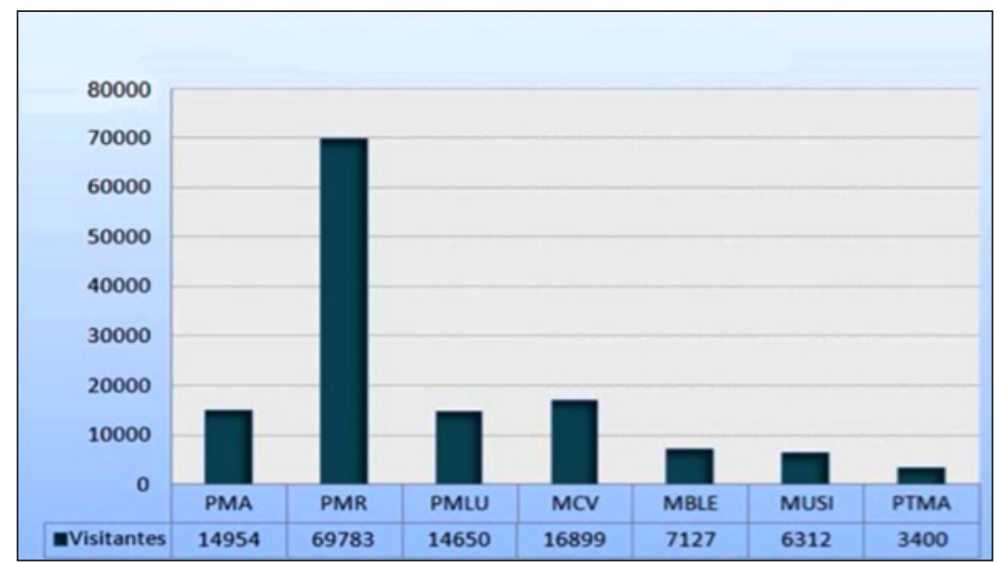

Tabla 4

DATOS PARA EL CÁLCULO DE CORRELACIÓN ISDS-NÚMERO DE VISITANTES (2010)

\begin{tabular}{|c|c|c|c|c|c|}
\hline $\begin{array}{l}\text { Centro } \\
\text { patrimonial }\end{array}$ & $\begin{array}{c}x \\
\text { ISDS }\end{array}$ & $\stackrel{\mathrm{y}}{\text { Visitantes }}$ & $x^{2}$ & $\mathrm{y}^{2}$ & xy \\
\hline PMA & 2,9 & 14.954 & 8,41 & 223.622 .116 & 43.367 \\
\hline PMR & 3,5 & 69.783 & 12,25 & 4.869 .667 .089 & 244.240 \\
\hline PMLU & 3,1 & 14.650 & 9,61 & 214.622 .500 & 45.415 \\
\hline $\mathrm{MCV}$ & 2,6 & 16.899 & 6,76 & 285.576 .201 & 43.937 \\
\hline MBLE & 3,0 & 7.127 & 9,0 & 50.794 .129 & 21.381 \\
\hline MUSI & 2,4 & 6.312 & 5,76 & 39.841 .344 & 15.149 \\
\hline PTMA & 2,0 & 3.400 & 4,0 & 11.560 .000 & 6.800 \\
\hline & 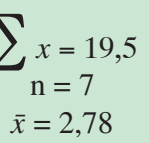 & $\begin{array}{c}\sum_{\substack{y=133.125 \\
n=7}} \\
\bar{y}=19.018\end{array}$ & $\begin{array}{c}55,79 \\
\bar{x}^{2}=7,73\end{array}$ & $\begin{array}{c}5.695 .683 .379 \\
\bar{y}^{2}=361.684 .324\end{array}$ & $\begin{array}{c}420.289 \\
\bar{x} \bar{y}=52.870\end{array}$ \\
\hline
\end{tabular}

Fuente: elaboración propia. 


\section{CONCLUSIONES}

El diagnóstico realizado en torno a las experiencias de nuevo uso turístico confirma que la sostenibilidad, medida a través de varios indicadores agrupados en componentes, ha vertebrado los proyectos emprendidos. No solo se ha recuperado el entorno natural y se han rehabilitado las arquitecturas abandonadas, también se ha propiciado la participación de las comunidades locales, se ha generado empleo, se ha procurado la mejor gestión de los recursos disponibles y se ha dotado de recursos económicos, aunque no siempre suficientes. La sostenibilidad se presenta en todos los casos como una apuesta de calidad y como un elemento de competitividad en los destinos turísticos de patrimonio industrial y minero.

A través del diseño de una metodología basada en la medición sencilla de indicadores y componentes, se ha alcanzado un índice sintético de desarrollo sostenible que ha permitido la comparación entre los distintos enclaves seleccionados. En particular debe destacarse el diferente nivel de sostenibilidad, siendo más importante en los ámbitos cultural, ambiental y socioeconómico que en el de gestión. En relación con los centros patrimoniales destaca especialmente el Parque Minero de Riotinto. En esa zona se aplicó, antes que en el resto, un proyecto de recuperación de gran alcance e interés turístico, lo que lo ha convertido en un claro referente. Otras experiencias más recientes tienen un grado de sostenibilidad menor, lo que indica que el objetivo del desarrollo sostenible se logra más fácilmente tras una cierta trayectoria temporal y la aplicación de estrategias a medio y largo plazo.

Ha quedado demostrado que existe vinculación entre turismo de patrimonio industrial y sostenibilidad, con una correlación positiva bastante elevada. En definitiva, la planificación y puesta en marcha de medidas de carácter sostenible tiene un gran significado para el incremento de visitantes y la atracción por un producto turístico tan específico, a la vez que territorial.

La recuperación de los elementos heredados de las industrias y minas constituye, en realidad, una de las mayores novedades del patrimonio histórico en España. Los proyectos analizados presentan una coherencia extraordinaria en lo que respecta a la cohesión de los aspectos ambientales, económicos y sociales, además de los puramente arquitectónicos. La sostenibilidad ha fundamentado, con mayor o menor intensidad aunque en todos los casos, las intervenciones practicadas y ha creado una especie de armonía que asocia, no sin problemas, turismo y desarrollo local.

En cualquier caso, y como reflexión de conclusiones, cabe hacerse algunas preguntasclave que habrán de fundamentar postreras investigaciones: ¿se han aplicado criterios coherentes de selección en la recuperación de las viejas estructuras productivas y extractivas?, ¿se enmarcan debidamente las actuaciones locales en un ámbito superior de intervención, bien regional o nacional?, ¿sirve de forma efectiva este patrimonio recuperado al relanzamiento económico de las áreas rurales afectadas por el declive?, ¿son temáticamente repetitivos algunos de los proyectos turísticos puestos en marcha?, ¿estas iniciativas dan respuesta a las necesidades reales de los territorios rurales?, ¿se deben considerar sostenibles las enormes sumas de dinero invertidas en los proyectos de recuperación, sobre todo teniendo en cuenta el número reducido de visitas?... Quizá es pronto para responder todos estos interrogantes, será cuestión de tiempo. 


\section{BIBLIOGRAFÍA}

AYUSO, A y otros (2008): Sostenibilidad local: una aproximación urbana y rural. Madrid. Observatorio de la Sostenibilidad en España.

AYUSO, A. y DELGADO, A. (Coord.) (2007): Patrimonio natural, cultural y paisajístico. Claves para la sostenibilidad territorial. Madrid. Observatorio de la Sostenibilidad en España.

BARRADO, D., HIDALGO, C. y PALACIOS, A. (2009): «Despoblación y envejecimiento en las zonas mineras. ¿Es el turismo una solución? Los casos de Riotinto y La PerníaBarruelo», en Despoblación, envejecimiento y territorio: un análisis sobre la población española (López, L., Abellán, A. y Godenau, D., Coords.). León, Universidad de León, pp. 629-642.

BENITO, P. (2002): «Patrimonio industrial y cultura del territorio». Boletín de la Asociación de Geógrafos Españoles, no 34, pp. 213-227.

BENITO, P. y ALONSO, P. (2012): «Industrial heritage and place identity in Spain: from monuments to landscapes». The Geographical Review, nº 102, 4, pp. 446-464.

BRAMWELL, B. y LANE, B. (1999): «Sustainable tourism: contributing to the debates». Journal of Sustainable Tourism, vol. 7, $\mathrm{n}^{\mathrm{o}}$ 1, pp. 1-5.

BUTLER, R. (1999): «Sustainable tourism: a state-of-the-art review». Tourism Geographies, vol. $1, \mathrm{n}^{\mathrm{o}} 1$, pp. $7-25$.

CAÑIZARES, M.C. (2008): «El atractivo turístico de una de las minas de mercurio más importantes del mundo: el Parque Minero de Almadén (Ciudad Real)». Cuadernos de Turismo, $\mathrm{n}^{\mathrm{o}}$ 21, pp. 9-31.

CAÑIZARES, M.C. (2011): «Protección y defensa del patrimonio minero en España». Scripta Nova, vol. XV, no 361 (http://www.ub.es/geocrit/sn/sn-361.htm>).

CARAVACA, I., COLORADO, D., FERNÁNDEZ, V., PANEQUE, P. y PUENTE, R. (1996): «Patrimonio cultural y desarrollo regional». EURE, 66, pp. 89-99.

CASTILLO, A. M., LÓPEZ, T.J. y MILLÁN, G. (2010): «El turismo industrial minero como motor de desarrollo en áreas geográficas en declive. Un estudio de caso». Estudios y perspectivas en turismo, vol. 19, $\mathrm{n}^{\circ} 3$, pp. 382-393.

COCCOSSIS, H. (1996): «Tourism and sustainability: perspectives and implications», en Sustainable tourism? European experiences (Priestley, G. K., Edwards, J. A. y Coccossis, H., Ed.). Oxford, CAB International, pp. 1-21.

COLE, D. (2004): «Exploring the sustainability of mining heritage tourism». Journal of Sustainable Tourism, vol. 12, n 6, pp. 480-494.

EDWARDS, J. A. y LLURDÈS I COIT, J. C. (1996): «Mines and quarries: industrial heritage tourism». Annals of Tourism Research, $\mathrm{n}^{\mathrm{o}} 23$, pp. 341-363.

FULLANA, P. y AYUSO, S. (2002): Turismo sostenible. Barcelona. Rubes Editorial.

HIDALGO, C. (2010): El patrimonio minero-industrial y ferroviario. Nuevos recursos para nuevos turismos. Madrid. Universidad Autónoma de Madrid. Tesis doctoral inédita.

JANSEN-VERBEKE, M. (1999): «Industrial heritage: a nexus for sustainable tourism development». Tourism Geographies, vol. 1, nº 1, pp. 70-85.

JANSEN-VERBEKE, M. (2009): «The territoriality paradigm in cultural tourism». Tourism, vol. $19, \mathrm{n}^{\mathrm{o}} 1-2$, pp. 25-31. 
PARDO, C.J. (2008): Turismo y patrimonio industrial. Un análisis desde la perspectiva territorial. Madrid, Editorial Síntesis.

PARDO, C.J. (2010a): «Industrial heritage sites and advanced models of tourism and culture promotion in Catalonia». Industrial Patrimony, $\mathrm{n}^{\circ} 23$, pp. 63-75.

PARDO, C.J. (2010b): «El patrimonio industrial en España: análisis turístico y significado territorial de algunos proyectos de recuperación». Boletín de la Asociación de Geógrafos Españoles, $\mathrm{n}^{\circ}$ 53, pp. 239-266.

PRATS, F. (2007): «Sostenibilidad y turismo, una simbiosis imprescindible». Estudios Turísticos, $\mathrm{n}^{\circ} 172-173$, pp. 13-62.

SANZ, C. (2008): «Fundamentos de sostenibilidad y desarrollo en la implantación de actividades turísticas en el medio rural». Estudios Turísticos, nº 177, pp. 91-98.

TAPIA, C. (2010): Estrategias de gestión del patrimonio industrial minero en España: el patrimonio como recurso de desarrollo local». Sevilla. Universidad de Sevilla.

TROITIÑO, M. A. (2007): «Estrategias sostenibles en destinos patrimoniales: de la promoción a la gestión integrada e innovadora». Estudios Turísticos, n $172-173$, pp. 225-232.

VAHÍ, A. (2010): «Patrimonio industrial como recurso para un turismo sostenible: la cuenca del Guadalfeo (Granada)». Cuadernos Geográficos, n 46, pp. 65-91.

VALENZUELA, M., PALACIOS, A. J. e HIDALGO, C. (2008): «La valorización turística del patrimonio minero en entornos rurales desfavorecidos. Actores y experiencias». Cuadernos de Turismo, nº 22, pp. 231-260.

VELASCO, M. (2009): «Gestión turística del patrimonio cultural: enfoques para un desarrollo sostenible del turismo cultural». Cuadernos de Turismo, no 23, pp. 237-253. 